Article

\title{
The Emotional Effects of Science Narratives: A Theoretical Framework
}

\author{
Helena Bilandzic *, Susanne Kinnebrock and Magdalena Klingler \\ Department of Media, Knowledge, and Communication, University of Augsburg, 86159 Augsburg, Germany; \\ E-Mails: helena.bilandzic@phil.uni-augsburg.de (H.B.), susanne.kinnebrock@phil.uni-augsburg.de (S.K.), \\ magdalena.klingler@phil.uni-augsburg.de (M.K.) \\ * Corresponding author
}

Submitted: 31 October 2019 | Accepted: 8 January 2020 | Published: 18 March 2020

\begin{abstract}
Stories have long been discussed as a tool to make science accessible to the public. The potential of stories to stimulate emotions in their audiences makes them an emotional communication strategy par excellence. While studies exist that test the effects of stories in science communication on the one hand and the effects of emotions on the other hand, there is no systematic elaboration of the mechanisms through which stories in science communication evoke emotions and how these emotions influence outcomes such as knowledge gain and attitude change. In this article, we develop a theoretical framework of the "Emotional Effects of Science Narratives" (EESN-Model), which includes a typology of emotions likely to arise from reading science communication as well as mechanisms for each of the emotions to evoke the (desired) outcomes. The model serves as a heuristic to delineate the emotional effects of narratives in science coverage and will help guide research in this domain to provide a deeper understanding of the role of emotion in science news.
\end{abstract}

\section{Keywords}

EESN-Model; emotional response; emotion; narrative; narrative effects; science communication

\section{Issue}

This article is part of the issue "Emotions and Emotional Appeals in Science Communication" edited by Monika Taddicken (Technische Universität Braunschweig, Germany) and Anne Reif (Technische Universität Braunschweig, Germany).

(C) 2020 by the authors; licensee Cogitatio (Lisbon, Portugal). This article is licensed under a Creative Commons Attribution 4.0 International License (CC BY).

\section{Introduction}

In the audience-based approach to science communication, the transmission of facts is less important than creating resonance with an audience's everyday world (Nisbet, 2009a). Accordingly, news coverage of science is less likely to present science in its complexity, but rather follows typical media logics, such as news factors, designed to create relevance and make the abstract tangible (Dunwoody, 2014). Specifically, studies have shown that narrative elements and dramatic human-interest stories are widely present in news coverage of science (Atkin, Smith, McFeters, \& Ferguson, 2008; Michelle, 2007; Nisbet, Brossard, \& Kroepsch, 2003). The potential of stories to stimulate emotions in readers and viewers make them an emotional communication strategy for science communication par excellence. For science cover- age, stories may have yet undiscovered power to serve as a format that is understood and liked by a broad lay public, as the recent lively debate about narratives in science communication shows (Avraamidou \& Osborne, 2009; Dahlstrom, 2014; Dahlstrom \& Scheufele, 2018; Kaplan \& Dahlstrom, 2017).

Narratives, or stories, are defined as representations of events in a certain chronological order connected by causality (Abbott, 2008). In addition, Fludernik (2010) emphasizes that another important defining element of narratives is the representation of characters and their experientiality, that is, their thoughts, feelings, intentions, and motivations. At least one of the two aspects-events and characters-is necessary for a narrative. Usually, both are present but the focus may lie on one or the other. Narratives are a common everyday mode of communication, and they facilitate information 
processing and memory by increasing interest, relevance, and attention (Green, Bilandzic, Fitzgerald, \& Paravati, 2019). They also motivate the reader to continue reading and trying to understand-Downs (2014) sees the potential of stories in science communication in their ability to serve as "self-motivating vehicle for information delivery" (p. 13628).

We develop a theoretical framework of narrative science communication that extends existing models of narrative persuasion and emotional effects. At the core, our model assumes that stories in science coverage often evoke emotional reactions, which support, inhibit or otherwise change the processing of science information. We do not consider all the different forms of science communication but restrict ourselves to journalistic media coverage of science issues. By focusing on this important type of science communication, we are able to be more specific regarding the stories and outline prototypical narratives, which are then used to develop the emotional implications, mechanisms, and effects for each of them. This is a restriction considering that the variations of stories are manifold. At the same time, the discussion of narratives in science communication often suffers from a lack of specification of the narratives. Consequently, our model adds to existing scholarship by making the nature of stories more precise and by providing a classification of narrative properties that have implications for the audience's emotional reactions.

\section{The Prototypical Science Stories}

First, we will elaborate on aspects that characterize prototypical stories used in science coverage. This first step can be considered a classification of stories according to their narrative properties that are particularly prone to evoking emotions in readers. Certainly, stories have more properties than the ones we describe below. And certainly, not all stories in science coverage have these properties. Rather, each of the four prototypical stories described below (narrative of progress through research, narrative of risk through research, plot-oriented narrative, and character-oriented narrative) can be considered an ideal type of science stories which may appear in a pure form or be combined with each other, or may appear emotionally intense or less so. The reason we include a classification of the media text in a model of effects is that the media text is commonly undertheorized-in science communication as well as narrative persuasion. The focus is usually on the processes that take place in the reader. For example, the transportation-imagery model (Green \& Brock, 2000) explains that readers immerse themselves in the story, generate vivid mental imagery and develop less counterarguing-all processes of the reader. Factors of the text are restricted to more general characteristics such as craftmanship (in the sense that stories by bestseller authors are more transporting). The same applies to other models of narrative effects such as the model of narrative understanding and engagement by Busselle and Bilandzic (2008) or the extended elaboration likelihood model by Slater and Rouner (2002). Approaches that reflect the use of stories in science communication also do not elaborate on the properties of stories (Dahlstrom, 2014). As a notable exception, Downs (2014) identifies three textual factors of the prescriptive scientific narrative in a synthesis of the literature: the narrator's voice, conflict/action, and resolution. Some experimental studies investigate specific properties of stories. For example, Dahlstrom and Rosenthal (2018) experimentally test differences in vivid narrative detail (e.g., character details, setting, and emotional descriptions) in a text on climate change. And Morris et al. (2019) test the effects of different emotional valences of the ending of a climate change story. All of these aspects are well-known properties of stories in general. For a model on science stories, it is important to identify patterns in the narrative text that are specific for science stories, and that offer firm grounds for deriving hypotheses on effects.

\subsection{Message Momentum}

Research demonstrates that two recurring themes in media coverage of science exist with clear implications for emotions: (1) narratives of progress through research, emphasizing the utility of research, and (2) narratives of risk through research, highlighting the dangers. We call this dimension the "message momentum" to denote a narrative pattern that presents research in a certain way (progress vs. risk), but at the same time is not identical to a mere evaluation.

First, narratives of progress through research present scientific research as beneficial and full of potential, ultimately helping society to further develop and increase its citizens' quality of life. Prototypical portrayals depict scientists as adventurers and brave heroes (Haynes, 2017), positively evaluated as productive and trustworthy (Van Gorp, Rommes, \& Emons, 2014). Thus, images are invoked of courageous scientists venturing into the unknown to transcend human boundaries, helping to dominate nature and the foreign, as well as serving to defend humans against impending dangers (Kinnebrock, Klingler, \& Bilandzic, 2019). Progress narratives are also transported in current media coverage of science by frames predominantly highlighting the potential for and benefits of scientific research. Frames, in a basic understanding, are aspects of an issue made salient in a text that suggest a certain interpretation and evaluation of the issue (Entman, 1993, p. 52). In the context of science coverage, several studies conclude that such frames of scientific progress are present throughout science coverage (Bubela, 2004; Lück, Wessler, Wozniak, \& Lycarião, 2018; Nisbet, 2009b) and new methods or procedures are often celebrated as "a genius-eureka science narrative" (González Santos, Stephens, \& Dimond, 2018, p. 430). To be clear, we do not equate frames and narratives. Conceptually, frames are different from narratives in that 
they do not need to represent events or characters but may also put forward an abstract argument. Thus, many frames are not narrative. However, narratives may very well serve as frames. Our point here is that researchers have found frames that express progress and that this has thematic closeness to our "narrative of progress through research."

Second, narratives of risk through research highlight the dangers of research and its possible negative effects on society. In a similar vein, frames in science coverage focusing on risks, uncertainties, and controversies (Nisbet, 2009b; Ruhrmann, Guenther, Kessler, \& Milde, 2015) convey messages of risk. Often, such narratives of risk through research resonate with and make use of master plots of science and scientists. Several studies show that scientists are not only presented as good but also as villains and "evil" or "mad" (Haynes, 2017). While these portrayals predominantly originate from fictional representations, themes like the Frankenstein motif are also used in current debates to convey the idea that certain scientific fields are dangerous, sparking public fear (Turney, 1998). Consequently, scientific research is also narrated as a threat to society-through either the loss of control over science, scientific hubris, or the willingness to sacrifice human lives (Kinnebrock et al., 2019). Several studies highlight the presence of these narratives as the dilemma of Pandora's box, Frankenstein's monster, or runaway science (Ancillotti, Holmberg, Lindfelt, \& Eriksson, 2017; Gschmeidler \& Seiringer, 2012; Nisbet, 2009b).

The two kinds of narrative (progress, risk) need to be understood as prototypes; they can appear in high and low intensity, but also in combinations with each other.

\subsection{Focus of the Story}

Apart from message momentum, we argue that the focus of the story in science news matters. Specifically, we distinguish between two fundamental foci of stories-plotoriented and character-oriented-based on the two basic components of narrative definitions, the plot and the characters (Abbott, 2008; Fludernik, 2010).

(1) Plot-oriented stories centre around events unfolding and actions being carried out. A prominent and frequent example in science coverage is the story of the research process (Bilandzic, Kinnebrock, \& Klingler, 2019). Such stories describe how an idea for a research project was developed and how the study was conducted. The following example of news on a scientific study on the evolution of moths exemplifies this focus:

A crime thriller regularly leads to the conclusion: It happened in a different way than everyone assumed....It is not only criminal investigators who reach this insight, but sometimes evolutionary biologists too. For example, when they tried to solve the mystery of when and why moths developed the ability to hear....To reconstruct exactly when moths developed hearing, the biologists had to proceed just as meticulously as investigators in a criminal case. [Akito] Kawahara and his colleagues [from the University of Florida] examined more than 2,000 genes from approximately 180 species of contemporary butterflies. Using this data and by comparing it with fossil discoveries, the researchers compiled an evolutionary genealogy allowing them to date important stages in the evolution of butterflies. (Blawat, 2019, translation by authors)

(2) Character-oriented stories focus on people and their ideas, thoughts, feelings, and motivations-essentially the component of narrative that Fludernik (2010) calls "experientiality," with a focus on human consciousness. In science coverage, we find two main versions of this focus (Bilandzic et al., 2019): First, stories about people affected by a research field, which includes, for example, stories of climate change victims. Also, study participants can be the main protagonists of a story in science coverage. Here is an example from a German newspaper about a woman who is driven from her home in the Marshall Islands due to climate change:

Mona Jetnil is ready. When she finally acquires a seat on the plane, she will leave her old life behind and start a new one....She will not take many things with her, only her few clothes, a cooler with food. And Witon, her youngest son....Mona Jetnil, 24 years old, hardly speaks any English and knows next to nothing about her destination: Springdale, Arkansas.....Mona only knows that life will be better than here in Majuro, the capital of the Marshall Islands....[Here,] the scarce land is becoming ever scarcer. For decades, the sea level has been rising, centimetre by centimetre....The ocean will devour one atoll after another, and Mona, her family, her neighbours, and her people will lose their land. (Hinzel, Jose, \& Wall, 2015, translation by authors)

Second, character-oriented stories can deal with the researchers themselves, with their careers, motivations and ideas, their hardships and lucky breaks. Researchers may be constructed as competitors working in the same field and try to defeat their opponent even using illegal methods to gain a competitive advantage (Bilandzic et al., 2019). The following example describes the story of a rival researcher working for a British biotech company that had released genetically modified mosquitos into natural habitats:

For the company, certainly, it is about profits, about millions. But there are still the good guys, researchers of integrity and idealistic activists. They get on to the bad guys. In this perspective, Luke Alphey would be the supervillain. With his boyish features and narrow stature, however, he would be a poor cast for this role. At most, it is the British man's occasional bursts of 
cackling laughter that would fit best....During his time at the university, it was the geneticist Alphey who developed the novel insects. (Von Bredow, 2012, translation by authors)

We propose that message momentum and focus of a story are the message elements that may elicit emotions in readers or viewers. We will substantiate this proposition in the following sections.

\section{Effects of Narratives and Mechanisms}

Research in narrative persuasion has shown that stories are effective in changing beliefs, attitudes, and behaviours, albeit with a small effect size (see metaanalysis by Braddock \& Dillard, 2016). Two mechanisms are usually identified as responsible for narrative effects (Bilandzic \& Busselle, 2013; Green et al., 2019): First, readers or viewers may strongly focus their mental capacity on a story and engage in intensive processing and elaboration of the story events (transportation or narrative engagement, see below). Second, the same intense focus on the story reduces critical thinking about the story's message and inhibits counterarguing, that is, the generation of negative thoughts about the story's assertions. The reduction of critical thinking is mainly due to the intense focus on the story: As being absorbed into a story is an enjoyable experience, people are motivated to avoid interrupting their pleasurable state by not questioning the narrative (e.g., Green, Brock, \& Kaufman, 2004). Reading a story, people lower their guard as they do not expect to be persuaded, so stories may "fly under the radar" (Dal Cin, Zanna, \& Fong, 2004). These processes do not automatically and always occur when reading a narrative; sometimes a narrative is not engaging and readers do not get or want to get involved.

Strong emotional and cognitive focus on the story, called transportation (Green \& Brock, 2000) or narrative engagement (Busselle \& Bilandzic, 2009), was shown to be an important mediator of effects in several metaanalyses (Tukachinsky \& Tokunaga, 2012; van Laer, de Ruyter, Visconti, \& Wetzels, 2014). Narrative engagement encompasses strong emotional components, and stories are considered a powerful means of eliciting emotions (Oatley, 1999). Regularly, the emotional component of narrative engagement proves to be the most effective mediator for effects (Busselle \& Bilandzic, 2009; de Graaf, Hoeken, Sanders, \& Beentjes, 2009).

While elaboration and a reduction in counterarguing are processes that also apply to non-narrative, rhetoric texts, narratives also allow for unique experiences and thus unique opportunities to change the audience's views. Narratives are condensed social experiences. Narratives told in science coverage portray researchers who have achieved great things, patients who suffer from rare illnesses, consumers who live plasticfree, or people who have had their DNA tested. Stories show that special and remarkable things happen to peo- ple, with more intensity and frequency than in actual life (otherwise these stories would not be newsworthy). In this account, stories are a simulation of social interactions (Mar \& Oatley, 2008) and allow the vicarious experience of the situations depicted, the ups and downs of the characters' fates (Bilandzic \& Busselle, 2013). By taking the perspective of the persons in the story, audience members understand from an inside perspective what it feels like to suffer from illness, and be healed, or experience failure in research, before ultimately winning a prestigious scientific award. More complex scenarios of future or possible situations enable vivid, closeto-life mental representations, for example, regarding the consequences of climate change (Bilandzic \& Sukalla, 2019). Identification with characters is closely related to vicarious experience. We understand identification as taking on the perspective of a character and emotionally and cognitively understanding what the characters go through and how they act (Cohen, 2001). Research has demonstrated that identification serves as an important mediator of narrative effects (Cohen, Tal-Or, \& Mazor-Tregerman, 2015; de Graaf, Hoeken, Sanders, \& Beentjes, 2012). For this reason, being able to relate to the characters is an important part of the narrative experience that is reflected in our model.

\section{Emotional Effects of Science Narratives: The EESN-Model}

Our model explains how narratives in science communication elicit emotions and how they influence a reader's information processing, knowledge, and attitudes. First, we develop a typology of emotions likely to arise from reading or viewing science coverage. Second, we develop mechanisms for each of the emotions to evoke the typical desirable outcomes for science communication: increased knowledge and trustworthiness of scientists, strengthened perceptions of the relevance and usefulness of science, and greater support for science (National Academies of Sciences, Engineering, and Medicine, 2017). The resulting model of "emotional effects of science narratives" (EESN-Model) serves as a heuristic to delineate the emotional effects of narratives in science coverage and will help to guide research in this domain to account for an elaborate view on the role of emotions (see overview in Figure 1).

We argued above that narratives in science coverage have two characteristics with implications for emotional reactions: Message momentum (narratives of progress vs. narratives of risk through research) and focus (character-oriented vs. plot-oriented) pave the way for specific emotional reactions, which we will elaborate below.

\subsection{Definition of Emotion}

Emotions are generally conceived as "internal, mental states representing evaluative, valenced reactions to 


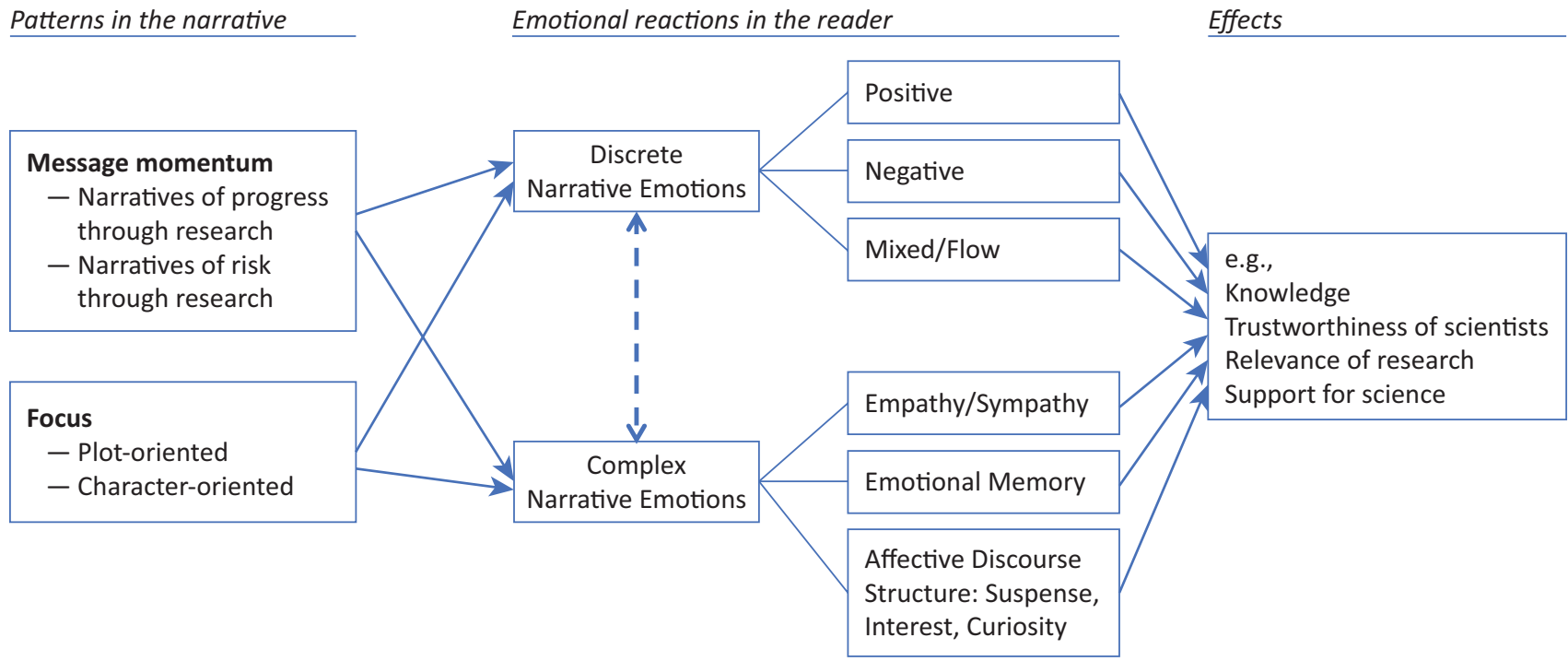

Figure 1. The EESN-Model.

events, agents, or objects that vary in intensity" (Nabi, 2019, p. 163). While many concepts of emotions exist, two perspectives are particularly prevalent in communication research (Nabi, 2019): first, dimensional models assume that emotions can be specified by their configuration along two or three dimensions. For example, the circumplex model of emotion by Russell (1980) places emotional states on the dimensions of (1) valence (from pleasant such as content or glad, to unpleasant such as sad or annoyed) and (2) arousal (from high arousal such as alarmed or excited, to low arousal such as bored or tired). Second, models of discrete emotions suggest that several emotional states exist which cannot be described using only a few dimensions; instead, there are "basic" emotional states (e.g., interest, joy/happiness, sadness, anger, disgust, and fear; see Nabi, 2010) that can be recognized by the facial expression of a person as well as by physiology or behavioural response (Ekman, 1992).

There are a number of connections between narratives and emotions. On a fundamental level, narratives may contain emotions, and they may evoke emotions in the reader. However, the basic definition of narrative as a representation of events and characters (Abbott, 2008; Fludernik, 2010) does not make the narrative contingent on the presence of emotion in the text itself. This reflects the fact that not all stories contain emotional elements. Nonetheless, even short stories such as media coverage of science may contain emotional elements, and if they do, we assume that they allow for emotional reactions in the reader and facilitate narrative effects.

Our model addresses "narrative emotions," which we define as emotions resulting from a reader's processing of narrative events and characters. Based on research in narrative experience and processing, we suggest that two types of narrative emotions may be elicited by narratives: First, discrete narrative emotions such as fear, hope, or guilt, which may be grouped into positive, negative, or mixed valences. Second, we assume that more complex narrative emotions arise from the interaction of the text and the reader. While discrete narrative emotions require a basic understanding of the story, we assume that complex narrative emotions are only perceived if readers have a sufficient level of narrative engagement in the story. In scholarship of discourse and reading psychology (e.g., Brewer \& Lichtenstein, 1982; Larsen \& Seilman, 1988; Oatley, 1999, 2002), we find three types of complex emotional reactions to narratives that are important drivers as well as elements of narrative engagement: (1) empathy and sympathy with the characters of the story, (2) emotion memories triggered by the text, and (3) responses to the affective discourse structure. We will detail these narrative emotions below, distinguish complex from discrete emotions, and describe their potential consequences for the readers.

\subsection{Discrete Narrative Emotions}

Narratives of progress and narratives of risk through research should evoke positive and negative emotions, respectively; the more a narrative makes the case for progress or risk, the stronger the emotional reactions should be. Of course, presenting both progress and risk is possible and quite common; in this case, mixed (ambivalent) emotions should arise (for example, both hope and fear).

To explain why narratives of progress and narratives of risk through research evoke emotions, we can make use of appraisal theories (e.g., Lazarus, 1991), and in particular Nabi's (1999) adaptation to media messages in her cognitive-functional model: a media message is first appraised according to its relevance for a person's own personal well-being. The resulting patterns of appraisal lead to the subjective perception of emotions. In particular, the "core relational themes," which represent harms and benefits apparent in the relationship between people and their environment, are connected to typical emo- 
tional reactions (Nabi, 1999, pp. 296-297): a "concrete and sudden danger of imminent physical harm" creates fear (matching our narratives of risk, which we assume to evoke fear), while "making reasonable progress toward the realization of our goals" creates happiness or joy (matching our narratives of progress, which we assume to evoke hope).

In general, emotions may serve as frames for the perception, processing, and effects of information (Nabi, 2019). The emotions-as-frames model (Nabi, 2003) suggests that media messages may contain information that triggers a certain emotion and is used as an interpretational foil for incoming stimuli. For example, reporting about the potential of genome editing to cure genetic disease in a patient may trigger hope in readers. According to the emotions-as-frames model, this emotion of hope will render information compatible with hope more accessible in memory and in turn will make subsequent judgments and actions also consistent with the emotion. In our case, the emotional response in the reader results from a narrative. We identified two prototypical stories in science communication, the story of progress and the story of risk through research. The link to emotions functions in a similar way as valence framing, where information is either presented in a positive or a negative light (Levin, Schneider, \& Gaeth, 1998), with the "positive light" being a gain frame describing the benefits of an action or outcome, and the "negative light" a loss frame describing the downsides or risks of an action or outcome. In effect, our stories of progress and risk through research may serve as gain and loss frames, which are known to elicit hope, and fear, respectively. Nabi et al. (2019) recently found in a meta-analysis that gain frames indeed elicit positive emotions, and loss frames elicit negative emotions, and both emotions enhance framing effects. Emotions here serve as mediators for effects between the frame in the text and the outcomes.

In addition to the predictions of the emotions-asframes model-that emotion-consistent information will be more accessible in memory and will influence judgments and actions in an emotion-consistent sensepositive and negative emotions (as well as mixed emotions) may have other consequences as well. Positive emotions elicited by narratives pave the way for a mindset that creates openness for differing views, as argued by broaden and build theory (Fredrickson \& Branigan, 2005). People who experience a positive emotion integrate bits of information more quickly, show less distortion or inflexibility in thinking, and are more open to new and unfamiliar information (Estrada, Isen, \& Young, 1997). Especially relevant to our topic of science communication, Fredrickson (2004) suggests that the positive emotion of interest "creates the urge to explore, take in new information and experiences, and to expand the self in the process" (p. 1369). Narratives are known to generate interest, which may, in turn, facilitate the processing and elaboration of the information "accompanying" the narrative. In general, Fredrickson (2004) argues that positive emotions foster action-thought tendencies of play, exploration, and integration rather than the narrowing action-thought tendencies of negative emotions which involve alarm and threat, triggering the reactions of "escape, attack, expel" (p. 1369). In threatening situations such as these, evolution dictates that it is beneficial for the individual not to linger and think but to run and think later.

While emotions elicited in a narrative context have not yet been explored in science communication, there is some evidence that (non-narrative) positive emotions foster beliefs and attitudes. For example, Smith and Leiserowitz (2014) found that interest and hope predicted global warming policy support. Several studies established that hope was a mediator of effects (Bilandzic, Kalch, \& Soentgen, 2017; Chadwick, 2015; Feldman \& Hart, 2016, 2018; Nabi, Gustafson, \& Jensen, 2018).

Whereas the broaden and build theory predicts a general narrowing of information processing as a response to negative emotions, research on fear appeals (a message that describes a threat) has shown that fear generally facilitates persuasive outcomes (Myrick \& Nabi, 2017) and serves as a robust persuasive strategy (Tannenbaum et al., 2015). This is not a contradiction but simply evidence for different information processing in the presence of positive and negative emotion. With the negative emotion of fear, information processing is narrow and probably focused on immediate actionrelevant aspects. Readers take in the message but do not spend time seeking further information or integrating other arguments.

Again, fear was not yet investigated as a consequence of reading stories in science coverage, but there are a number of studies finding that fear elicited by science coverage mediates related persuasive outcomes (e.g., Bilandzic et al., 2017; Spence \& Pidgeon, 2010).

Nabi argues that it is not the single emotion of fear that is effective but the emotional sequence within a story-the emotional flow (Nabi, 2015; Nabi \& Green, 2015). In a study on climate change communication, Nabi found that participants experienced more hope to a threat message when it was accompanied by an efficacy message; the emotional flow from fear to hope was the most effective influence on advocacy behaviour ( $\mathrm{Nabi}$ et al., 2018).

\subsection{Complex Narrative Emotions}

As for the focus of the story, stories about affected people and researchers are essentially about characterstheir fate, actions, and especially their feelings, thoughts, and motives. This invites the reader to feel with and about the character (empathy and sympathy). Also, readers may be reminded of their own experiences and emotions (emotion memories). Stories that focus on the scientific process may capture readers through the structure employed in the story, which may create experiences such as surprise, curiosity, and suspense. 


\subsubsection{Empathy and Sympathy}

The readers can assume the perspective of the character and engage in empathy and sympathy. Empathy describes the phenomenon where the readers share the feelings of a character; to feel anger, when the characters are angry, or fear, when the characters are fearful (Oatley, 2002). In contrast, sympathy denotes feelings of the reader about the character, feeling with and for the character rather than just feeling the same way (Oatley, 2002). A reader may feel pity or shame for the character when the character herself feels anger. For example, the newspaper excerpt cited earlier about the mother from the Marshal Islands, states:

Her older sons, Peterson, 6, and Ranson, 4, are sitting on the floor, cooking ramen noodles on a propane gas stove. They do not yet know that their mother will leave them behind. Mona has not yet dared to tell them. She did not have enough money for them. Their father will look after them and follow later, when Mona has saved enough money for the expensive tickets to the US. (Hinzel et al., 2015, translation by authors)

This text is suitable to create empathy with the mother and make the reader feel heartbroken; at the same time, readers may feel pity for the woman who is in such a desperate situation that she has to leave her children behind.

Intertwined with empathy and sympathy is the idea of affective disposition theory that audience members form positive dispositions towards protagonists or characters who behave in a morally acceptable way, and form negative dispositions towards antagonists or characters who behave in a morally unacceptable way (Raney, 2011). These positive and negative emotions, as well as feelings of empathy and sympathy, will influence how readers or viewers process information from science coverage and how they evaluate what happens to the characters. In affective disposition theory, audience members enjoy it when characters they like experience positive outcomes. Accordingly, audience members may pay selective attention to and recall specific facts that are beneficial for the story's characters but not those that are detrimental. Through processes of empathy with a favoured character, readers or viewers will share the cause of the character and attribute greater relevance to the scientific domain and be more supportive of science policy. This process is akin to motivated reasoning (Jain \& Maheswaran, 2000). And this form of motivated reasoning, again, is shaped by the narrative, rather than pre-existing attitudes and world views (Druckman \& Bolsen, 2011; Hart \& Nisbet, 2012).

A similar idea is expressed in the cognitive-functional model of emotions, in which Nabi (1999) suggests that negative emotions drive motivated attention and motivated processing of a message. Negative emotions that imply avoidance such as fear, disgust, and guilt, will reduce the motivation to attend to (motivated attention) and to process the remainder of the message (motivated processing). Negative emotions that imply approach such as anger and sadness will increase both motivated processes.

\subsubsection{Emotion Memories}

A vivid story of a person going through some extraordinary fate, hardship, or lucky circumstance, allows the reader to retrieve similar experiences from their own lives and evoke emotion memories (Oatley, 1999). These emotion memories from a person's own life serve to intensify the narrative experience, as both narrative and remembered emotions mingle together. Dill-Shackleford, Vinney, and Hopper-Losenicky (2016) accordingly suggest an interaction between personal and narrative processing in the process of "dual empathy": readers of stories feel empathy for the character and at the same time for themselves. Resonance of stories with the readers' lives is well documented in research on "remindings" (Larsen \& Seilman, 1988). Similarly, Dunlop, Wakefield, and Kashima (2008) assume that emotional responses may be elicited by the content of the message (message-referent emotional responses, for example, disgust at seeing effects of smoking on the lung) as well as by the plot (plot-referent emotional responses, for example, feeling sadness for a lung cancer victim). Both of these emotional responses may then trigger "selfreferent emotional responses," emotions in response to one's thoughts about one's life and self-which is the same concept as emotion memories.

As a consumer of science coverage is reminded of his or her own experiences and past emotions, the information may become more relevant and be processed in a more involved way. An example from science coverage may be a report about genetic testing for the risk of breast cancer, telling a story about a woman who had a prophylactic mastectomy at the age of 34 . This may trigger a memory of the reader's mother who also had breast cancer and died at an early age. The emotion memory associated may be a feeling of loss and grief for the mother, but also discrete emotions such as fear or anger.

Finally, while we think that emotion memories are most likely to arise in character-oriented narratives, we also assume that there is some fluidity: plot-oriented stories may also activate emotion memories, in the same way that Dunlop et al. (2008) elaborate that selfreferent emotional responses may arise from the emotions sparked by the plot.

\subsubsection{Affective Discourse Structure}

Stories about the scientific process invite emotional responses to the plot, or more precisely, the arrangement or structure of the plot. In their structural affect theory of stories, Brewer and Lichtenstein (1982) distinguish be- 
tween the event structure, that is a temporal sequence of events in a narrative world, and the discourse structure, which denotes the arranged sequence of events in a narrative. The discourse structure explains how something is told, as opposed to what is told on the event structure level. Different types of re-arrangement on the discourse level (that is, the affective discourse structure) have specific consequences for the emotional experience. Brewer and Lichtenstein (1982) identify three discourse structures:

(1) A structure creates surprise when crucial information is held back at the beginning and the readers are unaware that any information is missing. In the end, the information is revealed, forcing the readers to re-interpret the story. For example, consider a report in a German weekly newspaper on a rare genetic disorder that prevents people from feeling pain (Henk, 2014). A story is told of a young girl named May Linn who suffers from this disorder. A suspense structure could look like this: 'May Linn is a reckless child, fearing nothing and suffering frequent injuries. Her parents were accused of maltreatment for all the damage to the girl's body. Her toe had to be amputated because she had not paid attention to the wound. After years of seeking medical help, she received the diagnosis that she cannot feel pain because she has a rare genetic disorder.' In this example, the crucial information - that May Linn has a genetic disorderis held back until the end; reading the last sentence should evoke surprise.

(2) A structure generates curiosity when the beginning of a story starts to tell an event, but does not finish telling it. The reader is aware of the missing information and waits for it over the course of the story. In our example, a curiosity structure may look like this: 'After years of seeking medical help, May Linn received the diagnosis. She was a reckless child, fearing nothing and suffering frequent injuries. Her parents were accused of maltreatment for all the damage to the girl's body. Her toe had to be amputated because she did not pay attention to the wound. Her diagnosis was that she cannot feel pain because she has a rare genetic disorder.' In this example, the information that something is wrong with May Linn is given in the first sentence, but the information as to exactly what is wrong is omitted. Thus, the reader is aware of the missing information (unlike in the surprise structure where the reading is not aware that information is missing); the reader will wait for the diagnosis while reading the rest of the story.

(3) A structure facilitates suspense when the course of a story is uncertain. An initiating event is presented, but several outcomes are possible, which causes the reader to worry about the character and fear for their fate. The suspense structure is closest to the actual event structure. In our example, a surprise structure may look like this: 'May Linn was a reckless child, fearing nothing and suffering frequent injuries. Her toe had to be amputated because she did not pay any attention to the wound. After years of seeking medical help, she received the diagnosis that she cannot feel pain due to a rare genetic disorder. When she was a teenager, she thought she was going to die soon when she read that people without the ability to feel pain rarely reach their twenties. The doctors told her that she would never be able to have children, yet today, May Linn is in her thirties, she has made her home in London and given birth to two children.' For the reader, getting to know the different dangers of this particular disease opens up a series of possible outcomes for May Linn, all of which are negative. The last sentence states the outcome, which in this case is positive. Brewer and Lichtenstein (1982) emphasize that between the initiating event and the actual outcome, most often we find additional discourse, stretching the period in which the reader is uncertain of the character's fate.

The effect of all three discourse structures is that readers are drawn into the story and become motivated to continue reading. Also, an intense story will be retained in memory to a greater extent. While a plotoriented story may not seem like a very emotional part of the text, it can evoke emotional reactions in the reader by making use of affective discourse structures and stimulating surprise, curiosity, or suspense.

\subsubsection{Distinction between Complex Narrative Emotions and Discrete Narrative Emotions}

Complex narrative emotions require the reader to get involved in a story, for example, to assume the perspective of a character, to try to understand the situation and what it means for the character, or to play along with the author's way of telling a story and experience surprise, curiosity, or suspense. Complex narrative emotions are based on a higher level of narrative processing, in which the reader intensively follows the story, and they are more complex because the process by which a narrative evokes emotions is more complex. Conversely, for discrete emotions, the minimum requirement is lower: Readers simply need to make sense of the story in order to perceive discrete emotions. This does not mean, however, that higher levels of narrative engagement are incompatible with discrete emotions-on the contrary, discrete emotions may also appear in states of intense narrative experiences. They can be part of the more complex emotions. In the prophylactic mastectomy example, the emotional memory of grief for the mother may encompass the discrete emotion of sadness. Discrete emotions may be included in the more complex ones, but the more complex ones need more processing effort on the part of the reader.

\section{Conclusions}

Our EESN-model offers a heuristic for research on the emotional impacts of stories in science coverage and shows possible pathways of emotional reactions to prototypical stories. Rather than using generic properties 
of stories (such as narrative perspective, writing quality etc.), we provide a classification of stories that is specific for science coverage and identifies typical patterns in science story content resulting in four prototypical stories arranged on two dimensions: On the dimension of momentum, stories may (1) describe the dangers of research and possible negative effects on society (narratives of risk through research). Other stories may (2) describe scientific research as beneficial and advantageous for society and the quality of life of its citizens (narratives of progress through research). On the dimension of focus, stories may portray (3) scientists and people concerned by the scientific problem or research (characteroriented) or (4) the process of research (plot-oriented). This distinction is also ideal-typical, meaning that the classification describes the purest form and that actual empirical reality may contain weaker examples as well as combinations.

The EESN-model goes on to elaborate the different kinds of emotions that may be evoked, i.e., discrete narrative emotions (positive, negative, mixed emotions/emotional flow) as well as complex narrative emotions (empathy/sympathy, emotion memories, responses to affective discourse structure). It illuminates the mechanisms that may ultimately lead to effects, for example, on knowledge, understanding, the trustworthiness of scientists and science, the perception of relevance and usefulness of science, as well as support for science. The unique contribution of our model is that it focuses on emotional processing and reactions. It connects content properties with these emotional reactions and specific mechanisms for each pathway. The systematic connection between narrative content in a specific domain and ensuing processing and effects is what constitutes the theoretical progress compared to existing models of narrative persuasion. For example, neither the transportation-imagery model (Green \& Brock, 2000), nor the model of narrative understanding and engagement (Busselle \& Bilandzic, 2008), nor the extended elaboration likelihood model (Slater \& Rouner, 2002) make a distinction between different patterns in stories; all of these models suggest the same mechanisms for narrative persuasion (e.g., immersion, elaboration, reduced counterarguing, mental imagery). However, it seems appropriate to assume that stories with greater potential to trigger empathy will elicit different kinds of processing than stories that primarily work with suspense. And this is what our model calls for: a differentiated view on the narrative text, combined with a differentiated (and matching) view on processing and effects.

Our model also does not consider the factors of the reader or the communicator. We intended to create a theory that connects content, processing, and effects. This does not mean that other factors such as the reader's prior knowledge or credibility of the communicator are irrelevant. It only means that the theory is focused and, all else equal, the content factors and the emotional reactions we describe matter for effects.
Should researchers want to address reader characteristics in any future study, our model certainly needs to be combined with other theories. For example, to explore whether the effect of stories in climate change coverage depends on prior attitudes, we could complement our model with the value-belief-norm theory (Stern, Dietz, Guagnano, \& Kalof, 1999). This particular model suggests that existing environmental attitudes are relevant for behavioural outcomes. Thus, the propositions in the EESN-model will need to be combined with a moderator of prior environmental attitudes.

Finally, there are also risks of using narratives as a strategy in science communication. For example, processing the narrative may distract readers or viewers from the content of the actual message. This is particularly true for highly intense emotional cues which may steal attention away from the scientific issue and excessively highlight the emotion. The same is true for stories that do not integrate the facts or the persuasive message sufficiently into the story: In this case, the story will draw processing capacity away from the message and will not prove beneficial (Bilandzic \& Busselle, 2013). Moreover, a central mechanism of narrative persuasion is a reduction in counterarguing, that is, being less critical of the content. However, uncritical processing of media coverage on science may also have detrimental effects, because readers are more sensitive to assertions backed up by no or weak scientific evidence. This is certainly a crucial point when considering the value of narratives for science communication and may be responsible for some of the cautionary voices on this issue (e.g., Dahlstrom \& Ho, 2012). Narratives can serve as evidence or counterevidence for scientific findings - and it is up to the communicator to ensure that their narratives (especially those with a focus on characters) are representative, typical, and in accord with scientific insight. Similarly, there is a fine line between a gripping story that supports desired outcomes of science communication and a gripping story that overwhelms the reader to no avail. It requires a great deal of responsibility and sensitivity on the part of the communicator to cause the "proper" amount of emotion to be evoked by a story. More research is needed to delineate the effects of the different types of emotions we outlined in our model and to determine what stories on what scientific issues in what context are appropriate to serve as functional tools for science communication.

\section{Acknowledgments}

This work was supported by a grant of the German Research Foundation to Helena Bilandzic and Susanne Kinnebrock (grant no. BI 838/9-1 and KI 1532-/1-1).

\section{Conflict of Interests}

The authors declare no conflict of interests. 


\section{References}

Abbott, H. P. (2008). The Cambridge introduction to narrative (2nd ed.). Cambridge: Cambridge University Press.

Ancillotti, M., Holmberg, N., Lindfelt, M., \& Eriksson, S. (2017). Uncritical and unbalanced coverage of synthetic biology in the Nordic press. Public Understanding of Science, 26, 235-250. https://doi.org/10.1177/ 0963662515609834

Atkin, C. K., Smith, S. W., McFeters, C., \& Ferguson, V. (2008). A comprehensive analysis of breast cancer news coverage in leading media outlets focusing on environmental risks and prevention. Journal of Health Communication, 13, 3-19. https://doi.org/ 10.1080/10810730701806912

Avraamidou, L., \& Osborne, J. (2009). The role of narrative in communicating science. International Journal of Science Education, 31, 1683-1707. https://doi. org/10.1080/09500690802380695

Bilandzic, H., \& Busselle, R. W. (2013). Narrative persuasion. In J. P. Dillard \& L. Shen (Eds.), The Sage handbook of persuasion. Developments in theory and practice (pp. 200-219). Los Angeles, CA, and London: Sage.

Bilandzic, H., \& Sukalla, F. (2019). The role of fictional film exposure and narrative engagement for personal norms, guilt and intentions to protect the climate. Environmental Communication: A Journal of Nature and Culture, 13, 1069-1086. https://doi.org/ 10.1080/17524032.2019.1575259

Bilandzic, H., Kalch, A., \& Soentgen, J. (2017). Effects of goal framing and emotions on perceived threat and willingness to sacrifice for climate change. Science Communication, 39, 466-491. https://doi.org/ $10.1177 / 1075547017718553$

Bilandzic, H., Kinnebrock, S., \& Klingler, M. (2019). Stories of science: A content analysis of narratives and narrativity in newspaper coverage of genomic research. Unpublished manuscript.

Blawat, K. (2019, November 13). Forscher verwerfen Lehrbuchbeispiel der Evolution [Researchers revoke textbook example of evolution]. Sueddeutsche Zeitung. Retrieved from https://www.sueddeutsche. de/wissen/evolution-nachtfalter-fledermaeuse1.4680045

Braddock, K., \& Dillard, J. P. (2016). Meta-analytic evidence for the persuasive effect of narratives on beliefs, attitudes, intentions, and behaviors. Communication Monographs, 83, 446-467. https://doi.org/ 10.1080/03637751.2015.1128555

Brewer, W. F., \& Lichtenstein, E. H. (1982). Stories are to entertain: A structural-affect theory of stories. Journal of Pragmatics, 6, 473-486. https://doi.org/ 10.1016/0378-2166(82)90021-2

Bubela, T. M. (2004). Do the print media "hype" genetic research? A comparison of newspaper stories and peer-reviewed research papers. Canadian Medi- cal Association Journal, 170, 1399-1407. https://doi. org/10.1503/cmaj.1030762

Busselle, R. W., \& Bilandzic, H. (2008). Fictionality and perceived realism in experiencing stories: A model of narrative comprehension and engagement. Communication Theory, 18, 255-280. https://doi.org/ 10.1111/j.1468-2885.2008.00322.x

Busselle, R. W., \& Bilandzic, H. (2009). Measuring narrative engagement. Media Psychology, 12, 321-347. https://doi.org/10.1080/15213260903287259

Chadwick, A. E. (2015). Toward a theory of persuasive hope: Effects of cognitive appraisals, hope appeals, and hope in the context of climate change. Health Communication, 30, 598-611. https://doi. org/10.1080/10410236.2014.916777

Cohen, J. (2001). Defining identification: A theoretical look at the identification of audiences with media characters. Mass Communication \& Society, 4, 245-264. https://doi.org/10.1207/S15327825 MCS0403_01

Cohen, J., Tal-Or, N., \& Mazor-Tregerman, M. (2015). The tempering effect of transportation: Exploring the effects of transportation and identification during exposure to controversial two-sided narratives. Journal of Communication, 65, 237-258. https://doi.org/ 10.1111/jcom.12144

Dahlstrom, M. F. (2014). Using narratives and storytelling to communicate science with nonexpert audiences. Proceedings of the National Academy of Sciences of the United States of America, 111, 13614-13620. https://doi.org/10.1073/pnas.1320645111

Dahlstrom, M. F., \& Ho, S. S. (2012). Ethical considerations of using narrative to communicate science. Science Communication, 34, 592-617. https://doi.org/ $10.1177 / 1075547012454597$

Dahlstrom, M. F., \& Rosenthal, S. (2018). Third-person perception of science narratives: The case of climate change denial. Science Communication, 40, 340-365. https://doi.org/10.1177/1075547018766556

Dahlstrom, M. F., \& Scheufele, D. A. (2018). (Escaping) the paradox of scientific storytelling. Plos Biology, 16, 1-4. https://doi.org/10.1371/journal.pbio.2006720

Dal Cin, S., Zanna, M. P., \& Fong, G. T. (2004). Narrative persuasion and overcoming resistance. In E. S. Knowles \& J. A. Linn (Eds.), Resistance and persuasion (pp. 175-191). Mawah, NJ: Erlbaum.

de Graaf, A., Hoeken, H., Sanders, J., \& Beentjes, H. (2009). The role of dimensions of narrative engagement in narrative persuasion. Communications: European Journal of Communication Research, 34, 385-405. https://doi.org/10.1515/comm.2009.024

de Graaf, A., Hoeken, H., Sanders, J., \& Beentjes, J. W. J. (2012). Identification as a mechanism of narrative persuasion. Communication Research, 39, 802-823. https://doi.org/10.1177/0093650211408594

Dill-Shackleford, K. E., Vinney, C., \& Hopper-Losenicky, K. (2016). Connecting the dots between fantasy and reality: The social psychology of our engagement 
with fictional narrative and its functional value. Social and Personality Psychology Compass, 10, 634-646. https://doi.org/10.1111/spc3.12274

Downs, J. S. (2014). Prescriptive scientific narratives for communicating usable science. Proceedings of the National Academy of Sciences of the United States of America, 111, 13627-13633. https://doi.org/ 10.1073/pnas.1317502111

Druckman, J. N., \& Bolsen, T. (2011). Framing, motivated reasoning, and opinions about emergent technologies. Journal of Communication, 61, 659-688. https://doi.org/10.1111/j.1460-2466.2011.01562.x

Dunlop, S., Wakefield, M., \& Kashima, Y. (2008). Can you feel it? Negative emotion, risk, and narrative in health communication. Media Psychology, 11, 52-75. https://doi.org/10.1080/15213260701853112

Dunwoody, S. (2014). Science journalism: Prospects in the digital age. In M. Bucchi \& B. Trench (Eds.), Routledge handbook of public communication of science and technology (2nd ed., pp. 27-39). New York, NY: Routledge.

Ekman, P. (1992). An argument for basic emotions. Cognition and Emotion, 6(3/4), 169-200. https://doi.org/ 10.1080/02699939208411068

Entman, R. M. (1993). Framing: Toward clarification of a fractured paradigm. Journal of Communication, 43, 51-59.

Estrada, C. A., Isen, A. M., \& Young, M. J. (1997). Positive affect facilitates integration of information and decreases anchoring in reasoning among physicians. Organizational Behavior and Human Decision Processes, 72, 117-135. https://doi.org/10.1006/obhd. 1997.2734

Feldman, L., \& Hart, P. S. (2016). Using political efficacy messages to increase climate activism: The mediating role of emotions. Science Communication, 38, 99-127. https://doi.org/10.1177/1075547015617941

Feldman, L., \& Hart, P. S. (2018). Is there any hope? How climate change news imagery and text influence audience emotions and support for climate mitigation policies. Risk Analysis, 38, 585-602. https://doi.org/ 10.1111/risa.12868

Fludernik, M. (2010). Towards a 'natural' narratology (2nd. ed.). London and New York, NY: Routledge.

Fredrickson, B. L. (2004). The broaden-and-build theory of positive emotions. Philosophical Transactions of the Royal Society B-Biological Sciences, 359(1449), 1367-1377. doi:10.1098/rstb.2004.1512

Fredrickson, B. L., \& Branigan, C. (2005). Positive emotions broaden the scope of attention and thought: Action repertoires. Cognition \& Emotion, 19, 313-332. https://doi.org/10.1080/02699930441000238

González Santos, S. P., Stephens, N., \& Dimond, R. (2018). Narrating the first "three-parent baby": The initial press reactions from the United Kingdom, the United States, and Mexico. Science Communication, 40, 419-441. https://doi.org/10.1177/ 1075547018772312
Green, M. C., \& Brock, T. C. (2000). The role of transportation in the persuasiveness of public narratives. Journal of Personality and Social Psychology, 79, 701-721. https://doi.org/10.1037/0022-3514.79.5.701

Green, M. C., Bilandzic, H., Fitzgerald, K., \& Paravati, E. (2019). Narrative effects. In M. B. Oliver, A. A. Raney, \& J. Bryant (Eds.), Media effects. Advances in theory and research (4th ed., pp. 130-145). New York, NY, and London: Routledge.

Green, M. C., Brock, T. C., \& Kaufman, G. F. (2004). Understanding media enjoyment: The role of transportation into narrative worlds. Communication Theory, 14, 311-327. https://doi.org/10.1111/j.1468-2885. 2004.tb00317.x

Gschmeidler, B., \& Seiringer, A. (2012). "Knight in shining armour" or "Frankenstein's creation"? The coverage of synthetic biology in German-language media. Public Understanding of Science, 21, 163-173. https://doi.org/10.1177/0963662511403876

Hart, P. S., \& Nisbet, E. C. (2012). Boomerang effects in science communication: How motivated reasoning and identity cues amplify opinion polarization about climate mitigation policies. Communication Research, 39, 701-723. https://doi.org/10.1177/ 0093650211416646

Haynes, R. D. (2017). From madman to crimefighter. The scientist in Western culture. Baltimore, MD: John Hopkins University Press.

Henk, M. (2014, January 23). Leben ohne Schmerz...aber mit vielen Wunden [Life without pain...but with many wounds]. Die Zeit. Retrieved from https://www.zeit. de/2014/05/leben-ohne-schmerz-genmutation

Hinzel, J. H., Jose, C., \& Wall, K. (2015, November 27). Wo die Welt gerade untergeht [Where the world is about to end]. Sueddeutsche Zeitung. Retrieved from https://gfx.sueddeutsche.de/wissen/2015-1127_Marshallinseln/chapter01.html

Jain, S. P., \& Maheswaran, D. (2000). Motivated reasoning: A depth-of-processing perspective. Journal of Consumer Research, 26, 358-371. https://doi.org/ $10.1086 / 209568$

Kaplan, M., \& Dahlstrom, M. F. (2017). How narrative functions in entertainment to communicate science. In K. Hall Jamieson, D. M. Kahan, \& D. A. Scheufele (Eds.), The Oxford handbook of the science of science communication (pp. 311-319). Oxford: Oxford University Press.

Kinnebrock, S., Klingler, M., \& Bilandzic, H. (2019). The never-ending science story: Master plots of science in the newspaper coverage of genomic research. Unpublished manuscript.

Larsen, S. F., \& Seilman, U. (1988). Personal remindings while reading literature. Text, 8, 411-429. https:// doi.org/10.1515/text.1.1988.8.4.411

Lazarus, R. S. (1991). Emotion and adaptation. New York, NY: Oxford University Press.

Levin, I. P., Schneider, S. L., \& Gaeth, G. J. (1998). All frames are not created equal: A typology and critical 
analysis of framing effects. Organizational Behavior and Human Decision Processes, 76, 149-188. https:// doi.org/10.1006/obhd.1998.2804

Lück, J., Wessler, H., Wozniak, A., \& Lycarião, D. (2018). Counterbalancing global media frames with nationally colored narratives: A comparative study of news narratives and news framing in the climate change coverage of five countries. Journalism, 19, 1635-1656. https://doi.org/10.1177/ 1464884916680372

Mar, R. A., \& Oatley, K. (2008). The function of fiction is the abstraction and simulation of social experience. Perspectives on Psychological Science, 3, 173-192. https://doi.org/10.1111/j.1745-6924.2008.00073.x

Michelle, C. (2007). 'Human clones talk about their lives': Media representations of assisted reproductive and biogenetic technologies. Media Culture \& Society, 29, 639-663. https://doi.org/10.1177/ 0163443707078425

Morris, B. S., Chrysochou, P., Christensen, J. D., Orquin, J. L., Barraza, J., Zak, P. J., \& Mitkidis, P. (2019). Stories vs. facts: Triggering emotion and action-taking on climate change. Climatic Change, 154, 19-36. https:// doi.org/10.1007/s10584-019-02425-6

Myrick, J. G., \& Nabi, R. L. (2017). Fear arousal and health and risk messaging. Oxford Research Encyclopedia of Communication. Retrieved from https:// oxfordre.com/communication/view/10.1093/ acrefore/9780190228613.001.0001/acrefore9780190228613-e-266

Nabi, R. L. (1999). A cognitive-functional model for the effects of discrete negative emotions on information processing, attitude change, and recall. Communication Theory, 9, 292-320. https://doi.org/10.1111/j. 1468-2885.1999.tb00172.x

Nabi, R. L. (2003). Exploring the framing effects of emotion: Do discrete emotions differentially influence information accessibility, information seeking, and policy preference? Communication Research, 30, 224-247. https://doi.org/10.1177/ 0093650202250881

Nabi, R. L. (2010). The case for emphasizing discrete emotions in communication research. Communication Monographs, 77, 153-159. https://doi.org/ 10.1080/03637751003790444

Nabi, R. L. (2015). Emotional flow in persuasive health messages. Health Communication, 30, 114-124. https://doi.org/10.1080/10410236.2014.974129

Nabi, R. L. (2019). Media and emotion. In M. B. Oliver, A. A. Raney, \& J. Bryant (Eds.), Media effects: Advances in theory and research (4th ed., pp. 163-178). New York, NY: Routledge.

Nabi, R. L., \& Green, M. C. (2015). The role of a narrative's emotional flow in promoting persuasive outcomes. Media Psychology, 18, 137-162. https://doi.org/ 10.1080/15213269.2014.912585

Nabi, R. L., Gustafson, A., \& Jensen, R. (2018). Framing climate change: Exploring the role of emo- tion in generating advocacy behavior. Science Communication, 40, 442-468. https://doi.org/10.1177/ 1075547018776019

Nabi, R. L., Walter, N., Oshidary, N., Endacott, C. G., LoveNichols, E., Lew, Z. J., \& Aune, A. (2019). Can emotions capture the elusive gain-loss framing effect? A meta-analysis. Communication Research. https:// doi.org/10.1177/0093650219861256

National Academies of Sciences, Engineering, and Medicine. (2017). Communicating science effectively: A research agenda. Washington, DC: The National Academies Press.

Nisbet, M. C. (2009a). The ethics of framing science. In R. Elliott (Ed.), Communicating biological sciences: Ethical and metaphorical dimensions (pp. 51-73). London: Routledge.

Nisbet, M. C. (2009b). Communicating climate change. Why frames matter for public engagement. Environment, 51, 12-23. https://doi.org/10.3200/ENVT.51. 2.12-23

Nisbet, M. C., Brossard, D., \& Kroepsch, A. (2003). Framing science: The stem cell controversy in an age of press/politics. The Harvard International Journal of Press/Politics, 8, 36-70. https://doi.org/10.1177/ $1081180 \times 02251047$

Oatley, K. (1999). A taxonomy of the emotions of literary response and a theory of identification in fictional narrative. Poetics, 26, 439-454. https://doi.org/ 10.1016/0304-422X(94)P4296-S

Oatley, K. (2002). Emotions and the story worlds of fiction. In M. C. Green, J. J. Strange, \& T. C. Brock (Eds.), Narrative impact: Social and cognitive foundations (pp. 39-69). Mahwah, NJ: Lawrence Erlbaum.

Raney, A. A. (2011). The role of morality in emotional reactions to and enjoyment of media entertainment. Journal of Media Psychology, 23, 18-23. https://doi. org/10.1027/1864-1105/a000027

Ruhrmann, G., Guenther, L., Kessler, S. H., \& Milde, J. (2015). Frames of scientific evidence: How journalists represent the (un)certainty of molecular medicine in science television programs. Public Understanding of Science, 24, 681-696. https://doi.org/10.1177/ 0963662513510643

Russell, J. A. (1980). A circumplex model of affect. Journal of Personality and Social Psychology, 39, 1161-1178. https://doi.org/10.1037/h0077714

Slater, M. D., \& Rouner, D. (2002). Entertainmenteducation and elaboration likelihood: Understanding the processing of narrative persuasion. Communication Theory, 12, 173-191.

Smith, N., \& Leiserowitz, A. (2014). The role of emotion in global warming policy support and opposition. Risk Analysis, 34, 937-948. https://doi.org/10.1111/risa. 12140

Spence, A., \& Pidgeon, N. (2010). Framing and communicating climate change: The effects of distance and outcome frame manipulations. Global Environmental Change: Human and Policy Dimensions, 20, 
656-667. https://doi.org/10.1016/j.gloenvcha.2010. 07.002

Stern, P. C., Dietz, T., Guagnano, G. A., \& Kalof, L. (1999). A value-belief-norm theory of support for social movements: The case of environmentalism. $\mathrm{Hu}$ man Ecology Review, 6, 81-97.

Tannenbaum, M. B., Hepler, J., Zimmerman, R. S., Saul, L., Jacobs, S., Wilson, K., \& Albarracin, D. (2015). Appealing to fear: A meta-analysis of fear appeal effectiveness and theories. Psychological Bulletin, 141, 1178-1204. https://doi.org/10.1037/a0039729

Tukachinsky, R., \& Tokunaga, R. S. (2012). The effects of engagement with entertainment. Communication Yearbook, 37, 287-321. https://doi.org/ 10.1080/23808985.2013.11679153

Turney, J. (1998). Frankenstein's footsteps: Science, genetics and popular culture. New Haven, CT: Yale Uni- versity Press.

Van Gorp, B., Rommes, E., \& Emons, P. (2014). From the wizard to the doubter: Prototypes of scientists and engineers in fiction and non-fiction media aimed at Dutch children and teenagers. Public Understanding of Science, 23, 646-659. https://doi.org/10.1177/ 0963662512468566

van Laer, T., de Ruyter, K., Visconti, L. M., \& Wetzels, M. (2014). The Extended Transportation-Imagery Model: A meta-analysis of the antecedents and consequences of consumers' narrative transportation. Journal of Consumer Research, 40, 797-817. https:// doi.org/10.1086/673383

Von Bredow, R. (2012, January 30). Armee der Killermücken [Army of killer mosquitoes]. Der Spiegel. Retrieved from http://magazin.spiegel.de/ EpubDelivery/spiegel/pdf/83774724

\section{About the Authors}

Helena Bilandzic is a Full Professor at the University of Augsburg, Germany. She earned her PhD from the LudwigMaximilians-Universität (Munich) in 2003, and her habilitation degree from the University of Erfurt in 2009. Helena Bilandzic has also taught at universities in Munich, Erfurt, Ilmenau, Berlin, Hamburg, and Friedrichshafen. Her current research interests include media effects related to the environment, science, health and morality, narrative experience and persuasion, and cultivation.

Susanne Kinnebrock is a Professor at the University of Augsburg, Germany. She earned her PhD in Communication from the Ludwig-Maximilians-Universität (Munich) in 2002 and has also taught at several European universities (Munich, Erfurt, Hamburg, Salzburg, Vienna, Aachen and Lisbon). Her research interests include European communication history, gender media studies, narrative journalism, and health communication.

Magdalena Klingler is a Research Associate at the University of Augsburg. She earned her MA degree in Media and Communication from the University of Augsburg in 2016. She works in the field of science and environmental communication. 